\title{
AC-DC OPF based Day-Ahead Electricity Nodal Price Prediction using an ANN
}

\author{
S. B. Warkad, \\ Electrical Engg., Deptt., \\ Vishesveraya National Institute \\ of Technology (VNIT), Nagpur, India \\ Dr. M. K. Khedkar, \\ Electrical Engg., Deptt., \\ Vishesveraya National Institute \\ of Technology (VNIT), Nagpur.
}

\author{
Dr. G. M. Dhole, \\ Electrical Engg.,Deptt., \\ S.S.G.M. College. of Engg., \\ Shegaon (M.S.)
}

\begin{abstract}
Electricity industries around the world have significantly restructured in order to improve their economic efficiency, reliability of power systems and accountability. Accurate prediction of day-ahead electricity nodal price has now become an important activity to address the system operations and price volatility in the restructured electricity market. This will facilitate the market participants to estimate the risk and have better market oriented decision making.

In order to meet the electricity demand and other benefits, many developing countries including India are adopting HVDC transmissions in their existing system. Developing countries need to address this practice while adopting suitable electricity nodal pricing scheme and its accurate prediction. This study aims at (1) motivations and relevance of present study, (2) presenting AC-DC OPF based nodal pricing and formulation of day-ahead nodal price prediction using Artificial Neural Networks, (3) presenting and comparing numerical results for a real system of developing country like India to demonstrate the rationality and feasibility of the proposed methodology.
\end{abstract}

\section{General Terms}

Nodal Price Prediction

\section{Keywords}

AC_DC Optimal Power Flow (OPF), Nodal Price Prediction, Artificial Neural Networks

\section{INTRODUCTION}

The electricity supply industries around the world have experienced extensive restructuring process from the vertically regulated monopoly to the competitive market to improve their economic efficiency, reliability of power systems and accountability [1-2]. Under it, the nodal or locational marginal pricing (LMP) is emerged as an important mode of energy pricing [3]. LMPs reveal vital information to the market participants about their bidding strategies and risk management and to the system operators to perform market dispatch and clearing decisions in network congested electricity markets.

In developing countries, the electricity demand have expected to more that double in coming years as compared to about 30 to $40 \%$ increase in developing countries is due to insufficient transmission and distribution capacity. Also in order to meet the electricity demand and to gain techno-economic benefits of investment, many developing countries now adopting HVDC transmissions in the existing AC transmission system [2]. Developing countries in this regard address these issues while adopting suitable electricity nodal pricing scheme and its accurate prediction.

The application of nodal pricing in this environment is to accurately predict the electricity prices. Market participants need price prediction information to maximize their profits in spot markets, to negotiate bilateral contracts so that they can hedge against risks of price volatility in spot market, to ensure investments recovery in the facility planning and measures to predict possible exercises of market power and detect gaming behaviors which leads to unreasonable prices [2, 3]. Also, forecasted prices provide system operators with measures to predict possible exercises of market power and detect gaming behaviors leading to unreasonable prices [2].

Several hard computational techniques like time series models, auto regressive and auto regressive integrated moving average (ARIMA) models [5], [6] and combination of wavelet transform (WT) and ARIMA techniques have been tried to predict electricity prices [7]. A generalized autoregressive conditional heteroskedastic $(\mathrm{GARCH})$ methodology is used to predict next-day electricity prices [8]. Though these techniques are found accurate, but are limited to a large amount of historical information and the computational cost.

Besides, several soft computational techniques based on Artificial Intelligence approach are also been proposed. [3] suggested Neural Networks (NNs) and fuzzy-c-means approach to forecast LMPs. [4] presented a WT based NN model to forecast price to improve the forecasting accuracy. [5] proposed a feedforward NNs for forecasting next-week electricity prices. [9] proposed selforganized map and support-vector machine for forecasting shortterm electricity price. [10] employed fuzzy inference system and least-squares estimation for short-term price forecasting in wholesale electricity markets. [11] proposed the use of two ANNs: the first to predict the day-ahead load and second to forecast the day ahead market clearing price (MCP). [12] suggested NNs and fuzzy logic modeling for forecasting energy prices. [13] developed Bayesian framework to analyze the uncertainties involved in a MCP prediction. [14] used NNs extended Kalman filter to predict MCP and confidence interval in a deregulated power market. A sensitivity analysis of similar day parameters is used to increase the accuracy of NNs and to forecast hourly electricity prices [15]. As these techniques do not require modeling the system; instead, they find an appropriate mapping between the several inputs and the output, usually learned from historical examples, thus being computationally more efficient. The advantages of ANNs of being able to approximate any nonlinear function and being able to solve problems where the input-output relationship is neither well defined nor easily computable, as ANNs are data-driven.

Since, relation between nodal prices and its influencing variables i.e. real and reactive demands, bus voltages and angles are nonlinear, therefore; NNs are well suited for the problem under study due to their ability to model the complex and non-linear relationship involved in price prediction. This paper demonstrated AC-DC OPF based nodal price methodology and used neural networks to predict peak day-ahead electricity nodal price in a restructured electricity markets. Several NNs like Feedforward Neural Network (FFN) with Back-propogation (BP) algorithm, Cascade Feedforward Neural Network (CFN) networks are used to predict day-ahead nodal prices.

This paper is organized as follows: Section II discusses the need of modeling electricity nodal price and applications of price prediction; Section III demonstrate the AC_DC OPF based nodal pricing methodology and day-ahead electricity price prediction by ANNs; Section IV evaluates the numerical results for real 
transmission system of India. Finally, section $\mathrm{V}$ gives the conclusion of this paper.

\section{MOTIVATION OF PRESENT STUDY}

Under electricity restructuring environment and in various time horizons, the applications of price forecasting are different. In the short-term horizon, market participants use price forecasts to decide their bidding strategies to maximize their profits in the dayahead or short-term forward market. Generating companies have to make decisions regarding unit commitment. They will only want their generators to be dispatched if it is profitable, and as these decisions are often required hours or days in advance, so they require price forecast in order to determine profitability. For the medium-term horizon, suppliers and consumers use price forecasts to optimize the proportions of forward market and bilateral contracts in their asset allocations. Price forecasts are also references in the negotiation of bilateral contracts. Also scheduled maintenance of generating plants have to be decided based on price forecast to manage offline period that will have the least impact on profitability. For the long-term time horizon, facility owners use the long-term price trends to ensure recovery and profitability of their investments in generation, transmission, and distribution. Also often forecast and models of nodal prices serve various applications in the operation of electricity markets. Many industries use and pay for electricity as an important input in their operations, they also require forecasts of prices to determine their own profitability. In many markets around the world, users are able to purchase contracts for electricity at a fixed price over a specified time. The valuation of such financial derivatives requires estimation of both the likely levels and volatility of nodal prices in order to determine fixed and fair price for the contract itself. Market or independent system operator needs accurate prediction of energy prices for market monitoring because the exercise of market power can increase the volatility of electricity prices. This also can be used to predict market monitoring indexes and measurements. The market power indexes such as The HerfindahlHirschman Index (HHI) is used to measure the concentration of market shares, the Residual Supply Index (RSI) is used to identify pivotal suppliers, and the price-cost margin index, i.e., Lerner Index, is used to calculate the markup of prices over marginal costs are commonly used indexes by market operator [9]

\section{AC-DC OPF BASED NODAL PRICE AND ANN PREDICTION}

\section{1: Electricity Nodal Price Formulation}

The AC-DC OPF based nodal pricing problem is formulated as follows

3.1.1 AC System Equations: Let $P=\left(p_{1}, \ldots, p_{n}\right)$ and $Q=$ $\left(\mathrm{q}_{1}, \ldots, \mathrm{q}_{\mathrm{n}}\right)$ for $\mathrm{n}$ bus system, where $\mathrm{p}_{i}$ and $\mathrm{q}_{i}$ be active and reactive power demands of bus- $i$ respectively. The variables in power system operation to be $\mathrm{X}=\left(\mathrm{x}_{1}, \ldots, \mathrm{x}_{\mathrm{m}}\right)$, i.e. real and imaginary bus voltages. Then the operational problem of a power system for given load $(\mathrm{P}, \mathrm{Q})$ can be formulated as OPF problem

$\begin{array}{ll}\text { Minimize } & f(\mathrm{X}, \mathrm{P}, \mathrm{Q}) \quad \text { for } \mathrm{X} \\ \text { Subject to } & \mathrm{S}(\mathrm{X}, \mathrm{P}, \mathrm{Q})=0\end{array}$

$$
\mathrm{T}(\mathrm{X}, \mathrm{P}, \mathrm{Q}) \leq 0
$$

where $S(X)=\left(s_{1}(X, P, Q), \ldots \ldots ., s_{n 1}(X, P, Q)\right)^{T}$ and $T(X)=\left(t_{1}(X\right.$ $\left.P, Q), \ldots \ldots, t_{n 2}(X, P, Q)\right)^{T}$ have $n_{1}$ and $n_{2}$ equations respectively, and are column vectors. Here $\mathrm{A}^{\mathrm{T}}$ represents the transpose of vector A.

$f(\mathrm{X}, \mathrm{P}, \mathrm{Q})$ is a scalar, short term operating fuel cost. The generator cost function $f_{i}\left(P_{G i}\right)$ in $\$ / M W h$ is considered to have cost characteristics represented by

$$
\mathrm{f}=\sum_{\mathrm{i}=1}^{\mathrm{NG}} \mathrm{a}_{\mathrm{i}} \mathrm{P}_{\mathrm{Gi}}^{2}+\mathrm{b}_{\mathrm{i}} \mathrm{P}_{\mathrm{Gi}}+\mathrm{c}_{\mathrm{i}}
$$

cost coefficient of the $i^{\text {th }}$ generator, NG is the generation buses.

The constraints to be satisfied during optimization are

(A) Vector of equality constraint such as power flow balance has represented as

$$
\begin{aligned}
& \mathrm{S}(\mathrm{X}, \mathrm{P}, \mathrm{Q})=0 \text { or } \\
& \mathrm{PG}_{\mathrm{G}}=\mathrm{P}_{\mathrm{D}}+\mathrm{P}_{\mathrm{dc}}+\mathrm{P}_{\mathrm{L}} \text { and } \mathrm{Q}_{\mathrm{G}}=\mathrm{Q}_{\mathrm{D}}+\mathrm{Q}_{\mathrm{dc}}+\mathrm{Q}_{\mathrm{L}}
\end{aligned}
$$

where $D$ is demand, $G$ is generation, ' $\mathrm{dc}$ 'is de terminal and $L$ is the transmission loss.

(B) The vector of inequality constraints includes upper and lower bounds of transmission lines, generation outputs, stability and security limits is represented as

$$
\mathrm{T}(\mathrm{X}, \mathrm{P}, \mathrm{Q}) \leq 0 \quad \text { or }
$$

(i) The max and min real and reactive power outputs of the generating sources are given by

$$
\begin{aligned}
& P_{G i}^{\min } \leq P_{G i} \leq P_{G i}^{\max } \quad\left(i \in G_{B}\right) \\
& \text { and } Q_{G i}^{\min } \leq Q_{G i} \leq Q_{G i}^{\max } \quad\left(i \in G_{B}\right)
\end{aligned}
$$

(ii) Bus voltage limits (Min/Max) to remain within a narrow range

$$
\left|V_{i}^{\min }\right| \leq\left|V_{i}\right| \leq\left|V_{i}^{\max }\right| \quad\left(\mathrm{i}=1, \ldots \ldots, \mathrm{N}_{\mathrm{B}}\right)
$$

where $\mathrm{N}_{\mathrm{B}}$ represents number of buses.

(iii) Power flow limits is the transmission line's thermal or stability limits capable of transmitting maximum power (MVA) flow through the lines and it is

$$
\mathrm{P}_{\mathrm{f}}^{\min } \leq \mathrm{P}_{\mathrm{f}} \leq \mathrm{P}_{\mathrm{f}}^{\max } \quad(\mathrm{f}=1, \ldots, \text { Noele })
$$

where Noele is No. of transmission lines.

Then, operating conditions of a combined ac-dc power system may described by the vector

$$
X=\left[\delta, V, x_{c}, x_{d}\right]^{t}
$$

where, $\delta$ and $V$ are the vectors of the phases and magnitude of the phasor bus voltages; $x_{c}$ is the vector of control variables and $x_{d}$ is the vector of dc variables.

3.1.2 DC System Equations: The following relationship is for the dc variables. Using the per unit (PU) system [15], the average value of the dc voltage of a converter connected to bus ' $i$ ' is

$$
V_{d i}=a_{i} V_{i} \cos \alpha_{i}-r_{c i} I_{d i}
$$

where, $\alpha_{i}$ is the gating delay angle for rectifier operation or the extinction advance angle for inverter operation; $r_{c i}$ is the commutation resistance, and $a_{i}$ is the converter transformer tap setting. By assuming a lossless converter, the equation of the $\mathrm{dc}$ voltage written as

$$
V_{d i}=a_{i} V_{i} \cos \varphi_{i}
$$

where, $\varphi_{i}=\delta_{\mathrm{i}}-\xi_{\mathrm{i}}$, and $\varphi$ is the angle by which the fundamental line current lags the line-to-neutral source voltage.

The real and reactive power flow in or out of the dc network at terminal ' $i$ ' may express as

$$
P_{d i}=V_{i} I_{i} \cos \varphi_{i} \quad \text { or } \quad P_{d i}=V_{d i} I_{d i}
$$$$
Q_{d i}=V_{i} I_{i} \sin \varphi_{i} \text { or } Q_{d i}=V_{i} a I_{i} \sin \varphi_{i}
$$

Equation (13) can substitute in the equation (5) to form part of the equality constraints. Based on these relationships, the operating condition of the dc system can describe by the vector

$$
X_{d}=\left[V_{d}, I_{d}, a, \cos \alpha, \varphi\right]^{t}
$$

The dc currents and voltages have related by the dc network equations. In ac case, references bus usually the bus of the voltage controlling de terminal operating under constant voltage (or constant angle) control is specified for each separate dc system. Here equations (1) - (3) are an OPF problem for the demand (P, Q). Newton's OPF method is used to get an optimal solution.

where, $P_{G i}$ is the real power output; $a_{i}, b_{i}$ and $c_{i}$ is the 
3.1.3 Electricity Nodal Price: The real and reactive power prices at bus ' $i$ ' is the Lagrangian multiplier value of the equality and inequality constraints. These values have calculated by solving the first order condition of the Lagrangian, partial derivatives of the Lagrangian with respect to every variable concerned [16]. Therefore the Lagrangian function (or system cost) of equation defined as

$$
L(X, \lambda, \rho, P, Q)=f(X, P, Q)+\lambda S(X, P, Q)+\rho T(X, P, Q)
$$

where, $\lambda=\left(\lambda_{1}, \ldots \ldots ., \lambda_{n}\right)$ is the vector of Lagrange multipliers concerning the equality constraints; $\rho=\left(\rho_{1}, \ldots \ldots \ldots, \rho_{n}\right)$ are the Lagrange multipliers concerning to the inequality constraints. Then at an optimal solution $(X, \lambda, \rho)$ and for a set of given $(P, Q)$, the nodal price of real power for each bus is expressed below for $i=$ $1, \ldots \ldots \ldots, \mathrm{n}$.

$$
\pi_{p, i}=\frac{\partial L(X, \lambda, \rho, P, Q)}{\partial_{p i}}=\frac{\partial f}{\partial_{p i}}+\lambda \frac{\partial S}{\partial_{p i}}+\rho \frac{\partial T}{\partial_{p i}}
$$

Here $\pi_{p, i}$ is the active nodal prices at bus ' $i$ ', respectively. Equation (16) can be view as the system marginal cost created by an increment of real power load at bus $i$. The above formulation is programmed in MATLAB.

\subsection{Artificial Neural Network}

ANNs are highly interconnected processing units inspired in the human brain and its actual learning process. Interconnections between units have weights that multiply the values which go through them. Also, units normally have a fixed input called bias. Each of these units forms a weighted sum of its inputs, to which the bias is added. This sum is then passed through a transfer function. Prediction with NNs involves two steps: training and learning. Training of NNs is normally performed in a supervised manner. In the learning process, a neural network constructs an input-output mapping, adjusting the weights and biases at each iteration based on the minimization or optimization of some error measure between the output produced and the desired output. This process is repeated until an acceptable criterion for convergence is reached.

This study used Feedforward Neural Networks to predict dayahead electricity nodal prices. The theoretical formulations are as follows

\subsubsection{FeedForward Neural Network (FFN) with} Backpropogation (BP) algorithm: A three layered feed forward NN with BP training algorithm possesses the ability to classify mixed datasets and can be used effectively in obtaining the correct prediction. For generalization, the randomized data is fed to the network and is trained for different hidden layers. The numbers of processing elements in the hidden layer are varied. The input is passed layer through layer until the final output is calculated, and it is compared to the real output to find the error. The error is then propagated back to the input adjusting the weights and biases in each layer. In order to accelerate the learning process, two parameters i.e. the learning rate and the momentum of the BP algorithm can be adjusted. The learning rate is the proportion of error gradient by which the weights should be adjusted. Larger values can give a faster convergence to the minimum. The momentum determines the proportion of the change of past weights that should be used in the calculation of the new weights.

The FFN consists of an input, hidden and output layers. Each neuron in a layer is connected to other neurons of the previous layer through adaptable synaptic weights $\boldsymbol{w}$ and biases $\boldsymbol{b}$, shown in Figure 1.

If the inputs of neuron $\mathrm{j}$ are the variables $\mathrm{x}_{1}, \mathrm{x}_{2}, \ldots, \mathrm{x}_{\mathrm{i}}, \ldots, \mathrm{x}_{\mathrm{N}}$, the output $u_{\mathrm{j}}$ of neuron $j$ is obtained as

$$
\mathrm{u}_{\mathrm{j}}=\varphi\left(\sum_{\mathrm{i}=1}^{\mathrm{N}} \mathrm{w}_{\mathrm{ij}} \mathrm{X}_{\mathrm{i}}+\mathrm{b}_{\mathrm{j}}\right)
$$

where $\mathrm{w}_{\mathrm{ij}}$ is the weight of the connection between neuron $j$ and $i$ th input; $b_{j}$ is the bias of neuron $j$ and $\varphi$ is the transfer (activation) function of neuron $j$.

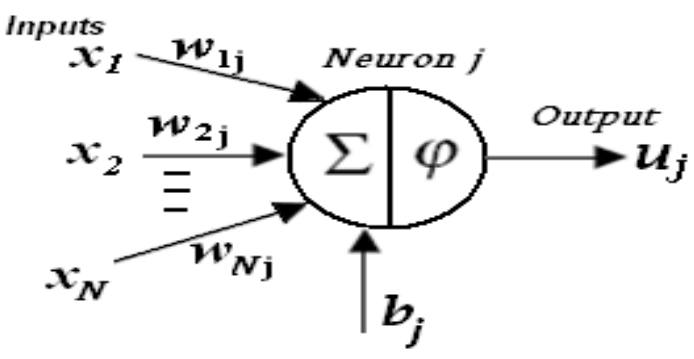

Figure 1(a): Information processing in a NN

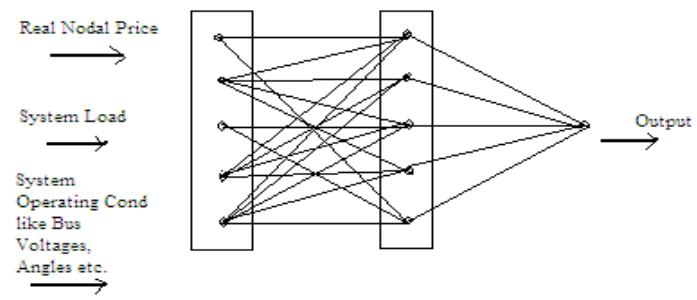

Figure 1(b): Proposed FFN for predicting nodal prices

An FFN is considered with N, M and Q neurons for the input, hidden and output layers, respectively. The input patterns of the ANN represented by a vector of variables $x=x_{1}, x_{2}, \ldots, x_{i}, \ldots$, $\mathrm{x}_{\mathrm{N}}$ ) submitted to the $\mathrm{NN}$ by the input layer are transferred to the hidden layer. Using the weight of the connection between the input and the hidden layer and the bias of the hidden layer, the output vector $u=\left(u_{1}, u_{2}, \ldots, u_{j}, \ldots, u_{M}\right)$ of the hidden layer is determined. The output $u_{j}$ of neuron $\mathrm{j}$ is obtained as

$$
u_{j}=\varphi \operatorname{hid}\left(\sum_{i=1}^{N} w_{i j}^{h i d} x_{i}+b_{j}^{h i d}\right)
$$

where $\mathrm{w}_{\mathrm{ij}}^{\text {hid }}$ is the weight of connection between neuron $j$ in the hidden layer and the $i$-th neuron of the input layer, $\mathrm{b}_{\mathrm{j}}^{\text {hid }}$ represents the bias of neuron $j$ and $\varphi$ hid is the activation function of the hidden layer.

The values of the vector $u$ of the hidden layer are transferred to the output layer. Using the weight of the connection between the hidden and output layers and the bias of the output layer, the output vector $y=\left(y_{1}, y_{2}, \ldots, y_{k}, \ldots, y_{Q}\right)$ of the output layer is determined.

The output $y_{k}$ of neuron $k$ (of the output layer) is obtained as

$$
\mathrm{y}_{\mathrm{k}}=\operatorname{\varphi out}\left(\sum_{\mathrm{j}=1}^{\mathrm{M}} \mathrm{w}_{\mathrm{jk}}^{\text {out }} \mathrm{u}_{\mathrm{j}}+\mathrm{b}_{\mathrm{k}}^{\text {out }}\right)
$$

where $\mathrm{w}_{\mathrm{jk}}^{\text {out }}$ is the weight of the connection between neuron $k$ in the output layer and the $j$-th neuron of the hidden layer, $b_{k}^{\text {out }}$ is the bias of neuron $k$ and $\varphi$ out is the activation function of the output layer.

The output $\mathrm{y}_{\mathrm{k}}$ is compared with the desired output (target value) $y_{k}^{d}$. The error $E$ in the output layer between $y_{k}$ and $y_{k}^{d}\left(y_{k}^{d}-\right.$ $\mathrm{y}_{\mathrm{k}}$ ) is minimized using the mean square error at the output layer (which is composed of $Q$ output neurons), defined by

$$
\mathrm{E}=\frac{1}{2} \sum_{\mathrm{k}=1}^{\mathrm{Q}}\left(\mathrm{y}_{\mathrm{k}}^{\mathrm{d}}-\mathrm{y}_{\mathrm{k}}\right)^{2}
$$


Training is the process of adjusting connection weights $w$ and biases $b$. In the first step, the network outputs and the difference between the actual (obtained) output and the desired (target) output (i.e., the error) is calculated for the initialized weights and biases (arbitrary values). In the second stage, these weights in all links and biases in all neurons are adjusted to minimize the error by propagating the error backwards (the BP algorithm). The network outputs and the error are calculated again with the adapted weights and biases, and this training process is repeated at each epoch until a satisfied output $y_{k}$ is obtained corresponding with minimum error. This is by adjusting the weights and biases of the BP algorithm to minimize the total mean square error and is computed as

$$
\begin{aligned}
& \Delta \mathrm{w}=\mathrm{w}^{\text {new }}-\mathrm{w}^{\text {old }}=-\eta \frac{\partial \mathrm{E}}{\partial \mathrm{w}} \quad \text { and } \\
& \Delta \mathrm{b}=\mathrm{b}^{\text {new }}-\mathrm{b}^{\text {old }}=-\eta \frac{\partial \mathrm{E}}{\partial \mathrm{b}}
\end{aligned}
$$

where $\eta$ is the learning rate. Equation (21) reflects the generic rule used by the BP algorithm. Equations (22) and (23) illustrate this generic rule of adjusting the weights and biases. For the output layer, we have,

$$
\begin{aligned}
& \Delta \mathrm{w}_{\mathrm{jk}}^{\text {new }}=\alpha \Delta \mathrm{w}_{\mathrm{jk}}^{\text {old }}+\eta \delta_{\mathrm{k}} \mathrm{y}_{\mathrm{k}} \text { and } \\
& \Delta \mathrm{b}_{\mathrm{k}}^{\text {new }}=\alpha \Delta \mathrm{b}_{\mathrm{k}}^{\text {old }}+\eta \delta_{\mathrm{k}},
\end{aligned}
$$

where $\mathbb{X}$ is the momentum factor (a constant between 0 and 1) and $\delta_{\mathrm{k}}=\mathrm{y}_{\mathrm{k}}^{\mathrm{d}}-\mathrm{y}_{\mathrm{k}} \quad$ For the hidden layer, we get,

$$
\begin{aligned}
& \Delta w_{i j}^{\text {new }}=\alpha \Delta w_{i j}^{\text {old }}+\eta \delta_{j} y_{j} \text { and } \\
& \Delta b_{j}^{\text {new }}=\alpha \Delta b_{j}^{\text {old }}+\eta \delta_{j}
\end{aligned}
$$

where $\delta_{\mathrm{j}}=\sum_{\mathrm{k}}^{\mathrm{Q}} \delta_{\mathrm{k}} \mathrm{w}_{\mathrm{jk}}$ and $\delta_{\mathrm{k}}=\mathrm{y}_{\mathrm{k}}^{\mathrm{d}}-\mathrm{y}_{\mathrm{k}}$

3.2.2 Cascade Feedforward Neural Network (CFN): In the cascading neural network, there are three types of nodes: input nodes, inner nodes and output nodes, denoted as $\mathrm{u}_{i}, i=1,2, \ldots, \mathrm{p}, \mathrm{e}_{i}$, $i=1,2, \ldots, \mathrm{n}$ and $\mathrm{y}_{i}, \mathrm{i}=1,2, \ldots, \mathrm{q}$ respectively. The function describing inner nodes may be represented as

$$
e_{j}=\phi\left(\sum_{j=1}^{p} w_{i j}^{e u} u_{j}+\sum_{k=1}^{i=1} w_{i k}^{e e} e_{k}+b_{i}^{e}\right)
$$

where, $\phi(\bullet)$ is the activation function, $\mathrm{w}_{\mathrm{ij}}^{\mathrm{eu}}, \mathrm{w}_{\mathrm{ik}}^{\mathrm{ee}}$ are adjustable weightings, $u_{j}, e_{k}$ are outputs from input and inner nodes respectively, $b_{i}^{e}$ is the bias term. The function describing the output nodes is purely linear and may be described as

$$
y_{j}=\left(\sum_{j=1}^{p} w_{i j}^{y u} u_{j}+\sum_{k=1}^{n} w_{i k}^{y e} e_{k}+b_{i}^{y}\right)
$$

where, $y_{j}$ is the output of the output node, $w_{i j}^{y u}, w_{i k}^{y e}$ are adjustable weightings, $\mathrm{u}_{\mathrm{j}}, \mathrm{e}_{\mathrm{k}}$ are outputs from input and inner nodes respectively, and $b_{i}^{y}$ is the bias term.

The training of CFN may be achieved using back propagation. The advantage of this NN is that it fully exploits the potentials of the links between neurons. Compared with other networks, this network uses less neuron for the same modeling or control problems.

\subsection{Price Prediction by ANNs}

The short-term electricity price prediction is determined by a balance between demand and supply. In a competitive electricity market, the objective of price formulation is either to minimize the generation cost or maximize the consumer benefits. So prices is most optimally obtained at various nodes or location of the network depending on the availability of low cost generation, real and reactive demands and availability of sufficient transmission capacity. In this study AC-DC OPF based nodal pricing methodology is used to obtained electricity prices at various nodes

\begin{tabular}{|c|c|c|c|}
\hline Particulars & Method/Value & Particulars & Method/Value \\
\hline \multicolumn{4}{|c|}{ For FFN and CFN } \\
\hline $\begin{array}{l}\text { Neural } \\
\text { network }\end{array}$ & $\begin{array}{l}\text { 'MLP'-BP } \\
\text { Algorithm }\end{array}$ & $\begin{array}{l}\text { Training } \\
\text { method }\end{array}$ & $\begin{array}{l}\text { 'Trainlm' } \\
\text { (Levenberg- } \\
\text { Marquardt BP) }\end{array}$ \\
\hline $\begin{array}{l}\text { No. of Input } \\
\text { neurons }\end{array}$ & 4 & $\begin{array}{l}\text { Learning } \\
\text { method }\end{array}$ & $\begin{array}{l}\text { 'learngdm' } \\
\text { (Gradient } \\
\text { decent } \\
\text { function) }\end{array}$ \\
\hline $\begin{array}{l}\text { No. of } \\
\text { output } \\
\text { Neurons }\end{array}$ & 1 & Learning rate & 0.5 \\
\hline \multirow[t]{2}{*}{$\begin{array}{l}\text { No. of } \\
\text { hidden } \\
\text { Layer }\end{array}$} & 1 & Momentum & $0.3-0.8$ \\
\hline & & $\begin{array}{l}\text { No. of } \\
\text { iterations }\end{array}$ & 100 \\
\hline $\begin{array}{l}\text { No. of } \\
\text { hidden } \\
\text { Neurons }\end{array}$ & 16 & $\begin{array}{l}\text { Data } \\
\text { dividation } \\
\text { method } \\
\end{array}$ & Dividerand \\
\hline \multirow{3}{*}{$\begin{array}{l}\text { Transfer } \\
\text { function }\end{array}$} & \multirow{3}{*}{$\begin{array}{l}\text { 'Tangent' } \\
\text { sigmoid', } \\
\text { 'Purelin' }\end{array}$} & $\begin{array}{l}\text { Data used for } \\
\text { training }\end{array}$ & $60 \%$ \\
\hline & & $\begin{array}{l}\text { Data used for } \\
\text { validation }\end{array}$ & $10 \%$ \\
\hline & & $\begin{array}{l}\text { Data used for } \\
\text { testing }\end{array}$ & $30 \%$ \\
\hline
\end{tabular}
at hourly peak demands obtained for several days. The obtained data are real nodal prices, bus voltages and angles, available real and reactive demands are used as input to above neural networks to predict the day-ahead prices. The neural network toolbox in MATLAB is selected and trained for various NNs with the ANN parameters as shown in Table 1 .

Table 1: ANN Parameters for Best Price Prediction

For the purpose of quantifying out-of sample prediction capability of the developed model, the nodal price prediction accuracy is evaluated and measured by using root mean square error (RMSE), mean absolute percentage error (MAPE), error variance, Forecast Mean Square Error (FMSE) and Standard Deviation (SD). The RMSE and MAPE are calculated, respectively, by

$$
\mathrm{RMSE}=\sqrt{\frac{1}{\mathrm{~N}} \sum_{\mathrm{i}=1}^{\mathrm{N}}\left(\text { Nodal Price }_{\text {predicted }}-\text { Nodal Price }_{\text {Re al }}\right)}
$$

MAPE $=\frac{100}{\mathrm{~N}} \sum_{\mathrm{i}=1}^{\mathrm{N}} \frac{\mid \text { Nodal Price }_{\text {predicted }}-\text { Nodal Price }_{\text {Re al }} \mid}{\text { Nodal Price }_{\text {Re al }}}$

Robustness of the applied methodology can be measured by means of statistical index, i.e., variance of error. The smaller the variance, the more precise is the predictions of nodal prices. The error variance is calculated by

$\gamma^{2}=\frac{1}{\mathrm{~N}} \sum_{\mathrm{i}=1}^{\mathrm{N}}\left(\frac{\mid \text { Nodal Price }_{\text {predicted }}-\text { Nodal Price }_{\text {Re al }} \mid}{\text { Nodal Price }_{\text {Re al }}}-\text { MAPE }\right)^{2}$

In addition, FMSE, which is the square root of the average of number of sample peak electricity nodal prices (daily), is the 
square differences between the predicted prices and the actual ones. A lower error indicates a better result. It is computed by

FMSE $=\sqrt{\frac{1}{N} \sum_{i=1}^{N}\left(\text { Nodal Price }_{\text {real }}-\text { Nodal Price }_{\text {predicted }}\right)^{2}}$

where $N$ is the number of sample peak electricity nodal prices (daily).

\section{NUMERICAL RESULTS}

\section{A Case Study of Indian Electricity MARKeT}

India's installed power generation capacity has increased from just $1.4 \mathrm{GW}$ in 1947 to over $150 \mathrm{GW}$ in 2009 . To improve the technofinancial performances of this sector, GoI enacted Electricity Act 2003 to enable framework for the overall development of wholesale electricity market. On the electricity transmission front, the National grid in the country is characterized by interconnection between Western, Northern, and North-Eastern regions of India, whereas Southern region is operating in asynchronous mode. Each one has number of constituent sub grids formed by state and private utility networks. All these sub grids and networks have connected to form a $400 \mathrm{kV}$ national grid. Maharashtra State utility has owned the largest installed capacity of $15,580 \mathrm{MW}$ in India. In 2005, it was unbundled into Generation, Transmission and Distribution companies.

This study considered a real network of $400 \mathrm{kV}$ Maharashtra State Electricity Transmission Company Limited (MSETCL), India shown in Figure A1 (Appendix). It consists of 19 intra-state buses (i.e. Bus No. 1 to 19) and 8 inter-state buses. To fulfill power demand, additional power is imported from inter-state generators. The generation data, fuel cost function of intra and inter-state generators expressed as $\left(f_{i}=a_{i} P_{G i}^{2}+b_{i} P_{G i}+c_{i}\right)$ in (\$/MWh) and operating data for HVDC link are shown in Table A1 and Table A2 (Appendix). The bus voltages have bounded between 0.95 and $1.05 \mathrm{PU}$.

The AC-DC OPF methodology is simulated for this real system for daily hourly average peak real and reactive power demands at various buses in the year 2008 are shown in Figure A1 (Appendix). The resulted bus voltages, angles and real electricity nodal prices are shown in Figure 2 and Figure 3.

To predict the day-ahead electricity nodal prices, the input variables mentioned in example 1 are assigned to various NNs and its parameters are selected as shown in Table I. Figure 3 shows the simulated results and comparison of average nodal price at various buses and predicted nodal prices. All the NNs attended more accurate nodal price prediction.

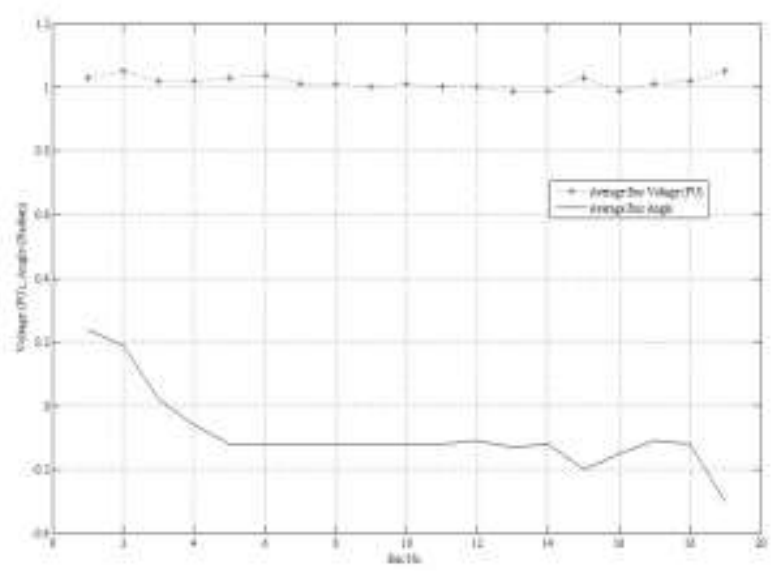

Figure 2: Average Voltage and Angle Variation

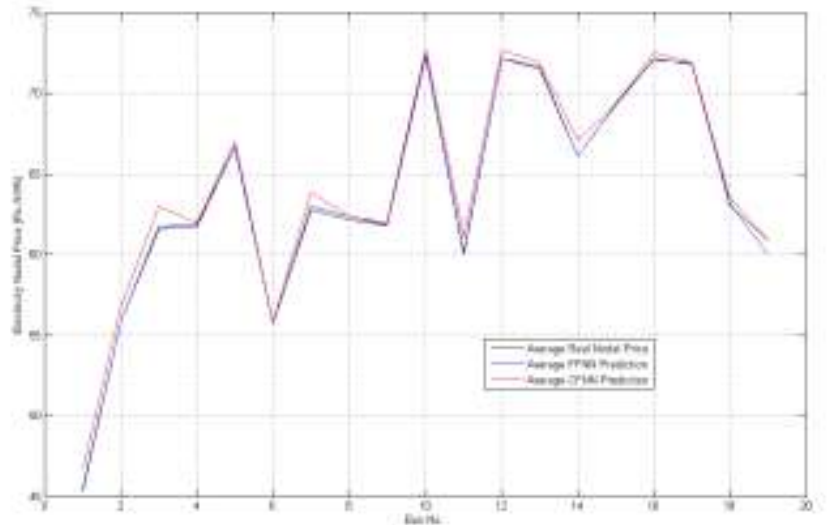

Figure 3: Electricity Nodal Price Prediction comparison

The performance of proposed NNs is evaluated by computing RMSE and MAPE. The resulted values for various buses are shown in Table II. Compared to other NNs, the RMSE in FFN is attended all positive values show more accurate prediction as compared to CFN neural networks. The error variance and FMSE comparison for various NNs is shown in Table II. FFN neural networks attended smaller variance gives more precise nodal prices predictions. FFN attended smaller FMSE values at several buses indicate a better prediction result.

Table 2: Error comparison

\begin{tabular}{|c|c|c|c|c|c|c|c|c|}
\hline $\begin{array}{c}\text { Bu } \\
\text { S }\end{array}$ & \multicolumn{2}{|c|}{ RMSE } & \multicolumn{2}{c|}{$\begin{array}{c}\text { MAPE } \\
(\boldsymbol{\%})\end{array}$} & \multicolumn{2}{c|}{ FMSE } & \multicolumn{2}{|c|}{ Variance } \\
\cline { 2 - 10 } No & FF & CF & FF & CF & FF & CF & FF & CF \\
. & N & N & N & N & N & N & N & N \\
\hline 1 & 0.4 & 0.4 & 0.3 & 0.6 & 0.4 & 0.6 & 0.1 & 0.4 \\
\hline 2 & 0.1 & -0.3 & 0.4 & 0.3 & 0.4 & 0.4 & 0.2 & 0.1 \\
\hline 3 & 0.4 & 0.6 & 0.9 & 0.8 & 0.8 & 0.8 & 0.8 & 0.7 \\
\hline 4 & 0.3 & -0.3 & 0.5 & 0.3 & 0.4 & 0.3 & 0.2 & 0.1 \\
\hline 5 & 0.1 & 0.6 & 0.7 & 0.8 & 0.7 & 0.7 & 0.5 & 0.6 \\
\hline 6 & 0.1 & 0.1 & 0.8 & 0.6 & 0.9 & 0.5 & 0.6 & 0.4 \\
\hline 7 & 0.5 & 0.2 & 0.5 & 0.6 & 0.8 & 0.7 & 0.2 & 0.3 \\
\hline 8 & 0.5 & 0.5 & 0.8 & 0.9 & 0.7 & 0.8 & 0.6 & 0.8 \\
\hline 9 & 0.3 & 0.4 & 0.6 & 0.9 & 0.9 & 0.8 & 0.4 & 0.8 \\
\hline 10 & 0.3 & -0.2 & 0.3 & 0.3 & 0.4 & 0.4 & 0.1 & 0.1 \\
\hline 11 & 0.4 & 0.4 & 0.6 & 0.9 & 0.7 & 0.9 & 0.3 & 0.8 \\
\hline 12 & 0.1 & 0.1 & 0.6 & 0.6 & 0.7 & 0.7 & 0.4 & 0.3 \\
\hline 13 & 0.4 & 0.3 & 0.3 & 0.4 & 0.7 & 0.4 & 0.1 & 0.2 \\
\hline 14 & 0.1 & 0.1 & 0.7 & 0.8 & 0.8 & 0.7 & 0.5 & 0.6 \\
\hline 15 & 0.3 & 0.4 & 0.5 & 0.8 & 0.5 & 0.7 & 0.2 & 0.6 \\
\hline 16 & 0.4 & 0.4 & 0.2 & 0.3 & 0.3 & 0.5 & 0.1 & 0.1 \\
\hline 17 & 0.4 & 0.2 & 0.5 & 0.5 & 0.7 & 0.4 & 0.3 & 0.2 \\
\hline 18 & 0.4 & 0.2 & 0.8 & 0.5 & 0.6 & 0.7 & 0.7 & 0.3 \\
\hline 19 & 0.4 & -0.1 & 0.6 & 0.8 & 0.9 & 0.6 & 0.3 & 0.7 \\
\hline
\end{tabular}

\section{CONCLUSION}

This study proposed new AC-DC OPF based methodology and use of ANN to predict day-ahead electricity nodal prices. The said methodology is implemented on real system of India and results are computed.

This paper demonstrates that NN can be suitably used to realize forecasting tasks, given its ability of simulating complex and nonlinear process, and its capacity to forecast.

The performances of the FFN network depend on the BP training algorithm. This study compares the performance of FFN with CFN. The simulation shows that the Levenberg-Marquardt algorithm has the fastest convergence in terms of iteration number and is able to obtain lower RMSE and MAPE error compared to CFN. Also FFN requires the lower amount of computation for low MSE for system 
under study. This advantage is mainly noticeable if very accurate quality level is required. The nodal price predictions obtained are accurate enough to be used by market participants to estimate the risk of price volatility in spot market, to ensure investments recovery and to predict exercises of market power etc. The proposed methodology is rational and more feasible for such developing countries to develop and maintain their wholesale market.

\section{REFERENCES}

[1] Ray, D. and Alvarado, F. Use of an engineering model for economic analysis in the electric utility industry. Advanced Workshop on Regulation and Public Utility Economics, 1998, May 25-27.

[2] S. B. Warkad S. B., Khedkar M. K., Dhole G. M. Economics of AC-DC OPF Based Nodal Prices for Restructured Electric Power System. International Journal of Electrical and Power Engineering.2009, 3 (6), 276-288

[3] Hong, Y.Y and Hsiao, C.Y. Locational marginal price forecasting in deregulated electricity markets using artificial intelligence. IEE Proc.-Generation, Transmission, Distribution, 149(5), 2002, 621-626.

[4] Aggarwal, S., Saini, L., and Ashwani Kumar. Electricity Price Forecasting in Ontario Electricity Market Using Wavelet Transform in Artificial Neural Network Based Model. International Journal of Control, Automation, and Systems, 6 (5), 2008, 639-650.

[5] Catal ao, J.P.S., Mariano, S.J.P.S., Mendesb, V.M.F. and Ferreira, L.A.F.M. Short-term electricity prices forecasting in a competitive market: A neural network approach. Electric Power Systems Research,39, 2007, 1297-1304.

[6] Contreras, J., Espínola, R., Nogales, F. J., and Conejo, A. J. ARIMA models to predict next-day electricity prices. IEEE Transactions. on Power System, 18 (3), 2003, 1014-1020.

[7] Conejo, A. J., Plazas, M. A., Espinola, R. and Molina, A. B. Day-ahead electricity price forecasting using the wavelet transform and ARIMA models. IEEE Transactions on Power System, 20 (2), 2005, 1035-1042.

[8] Garcia, R. Contreras, J., Akkeren, M. and Garcia, J. B. C. A GARCH forecasting model to predict day-ahead electricity prices. IEEE Transactions on Power System, 20 (2), 2005 , 867-874.

[9] Fan, S., Mao, C. and Chen L. Next-day electricity-price forecasting using a hybrid network. IET Generation Transmission Distribution, 1 (1), 2007, 176-182.

[10] Li, Guang, Liu, Ching, Mattson, Chris and Lawarrée, J. DayAhead Electricity Price Forecasting in a Grid Environment. IEEE Transactions on Power System, 22 (1), 2007, 266-274.

[11] Pavlos S., Georgilakis Artificial Intelligence solution to electricity price forecasting problem. Journal of Applied Artificial Intelligence, 21 (8), 2007, 707-727.

[12] Rodriguez, C. P. and Anders, G. J. Energy price forecasting in the Ontario competitive power system market. IEEE Transactions. on Power System, 19 (1), 2004, 366-374.

[13] Zhang, Li, Luh, Peter, B., and Kasiviswanathan, K. Energy Clearing Price Prediction and Confidence Interval Estimation
With Cascaded Neural Networks. IEEE Transactions on Power System, 18 (1), 2003, 99-105.

[14] Zhang, L. and Luh, P. B. Neural network-based market clearing price prediction and confidence interval estimation with an improved extended Kalman filter method. IEEE Transactions on Power System, 20 (1), 2005, 59-66.

[15] Mandal, P., Srivastava, A.K., and Park, Jung-Wook. An Effort to Optimize Similar Days Parameters for ANN-Based Electricity Price Forecasting. IEEE Transactions on Industry Applications, 45 (5), 2009, 1888-1896.

[16] Lu, C. N., Chen, S. S., Ong, C. M. The Incorporation of HVDC Equations in Optimal Power Flow Methods using Sequential Quadratic Programming Techniques. IEEE Transactions on Power System, 3 (3), 1988, 1005-1011.

[17] Chen, L., Suzuki, H., Wachi, T. and Shimura, Y. Components of Nodal Prices for Electric Power Systems. IEEE Transactions on Power System, 17 (1), 2002, 41-49.

\section{APPENDIX}

Table A1: Generator and HVDC Link Data

\begin{tabular}{|c|c|c|c|c|c|}
\hline \multirow{2}{*}{$\begin{array}{l}\text { Bus } \\
\text { No }\end{array}$} & \multirow[t]{2}{*}{ Generator } & \multirow{2}{*}{$\begin{array}{c}\text { Real } \\
\text { Generation } \\
\text { (PU) }\end{array}$} & \multicolumn{3}{|c|}{$\begin{array}{l}\text { Generation Cost } \\
\text { (\$/MWh) }\end{array}$} \\
\hline & & & $\mathbf{a}_{\mathbf{i}}$ & $\mathbf{b}_{\mathbf{i}}$ & $c_{i}$ \\
\hline \multicolumn{6}{|c|}{ Intra-State Generator } \\
\hline 1 & CHDPUR & 2.30 & 0.20 & 20.4 & 10.2 \\
\hline 2 & KORDY & 1.06 & 0.20 & 22.4 & 10.2 \\
\hline 12 & DABHOL & 1.50 & 1.02 & 71.4 & 10.2 \\
\hline 14 & KOYNA-4 & 1.50 & 0.20 & 20.4 & 10.2 \\
\hline \multicolumn{6}{|c|}{ Inter-State Generator } \\
\hline & BHILY & & 0.20 & 36.9 & 10.2 \\
\hline & KHANDWA & & 1.02 & 36.9 & 10.2 \\
\hline & SDSRV & & 1.02 & 77.6 & 10.2 \\
\hline & BOISR & & 1.02 & 55.7 & 10.2 \\
\hline & BDRVT & & 0.20 & 22.5 & 10.2 \\
\hline & TARAPUR & & 1.02 & 58.6 & 10.2 \\
\hline & SATPR & & 1.02 & 55.7 & 10.2 \\
\hline
\end{tabular}

Table A2: 400 kV MSETCL: $\pm 500 k V$ CHDPUR-PADGE HVDC Link

\begin{tabular}{|c|c|c|c|c|c|}
\hline Particulars & Data & Particulars & Data & Particulars & Data \\
\hline $\begin{array}{l}\text { Power } \\
\text { Flow } \\
\text { Rating }\end{array}$ & $\begin{array}{l}1500 \\
\text { MW }\end{array}$ & $\begin{array}{l}\text { Resistance } \\
\text { (1-Pole) } \\
\text { (2-Pole) } \\
\text { Metallic } \\
\text { Return }\end{array}$ & $\begin{array}{l}7.5 \\
\Omega \\
7.5 \\
\Omega \\
15 \\
\Omega \\
\end{array}$ & $\begin{array}{l}\text { Converter X'mer } \\
\text { Voltage of each } \\
\text { pole } \\
\text { Rated power/ unit }\end{array}$ & $\begin{array}{l}500 \\
\mathrm{kV} \\
298.6 \\
\text { MVA }\end{array}$ \\
\hline $\begin{array}{l}\text { Thyristor } \\
\text { Valves } \\
\text { Max. } \\
\text { voltage } \\
\text { Rated } \\
\text { current }\end{array}$ & $\begin{array}{l}7 \mathrm{kV} \\
1700 \\
\text { Adc }\end{array}$ & $\begin{array}{l}\text { HVDC } \\
\text { Line } \\
\text { Length of } \\
\text { line } \\
\text { No. of } \\
\text { poles }\end{array}$ & $\begin{array}{l}753 \\
\mathrm{Km} \\
2\end{array}$ & $\begin{array}{l}\text { Operation } \\
\text { CHDPUR- } \\
\text { Converter/Rectifier } \\
\text { PADGE-Inverter }\end{array}$ & $\begin{array}{l}12.5 \\
\text { to } 15^{\circ} \\
17 \text { to } \\
22^{\circ}\end{array}$ \\
\hline
\end{tabular}




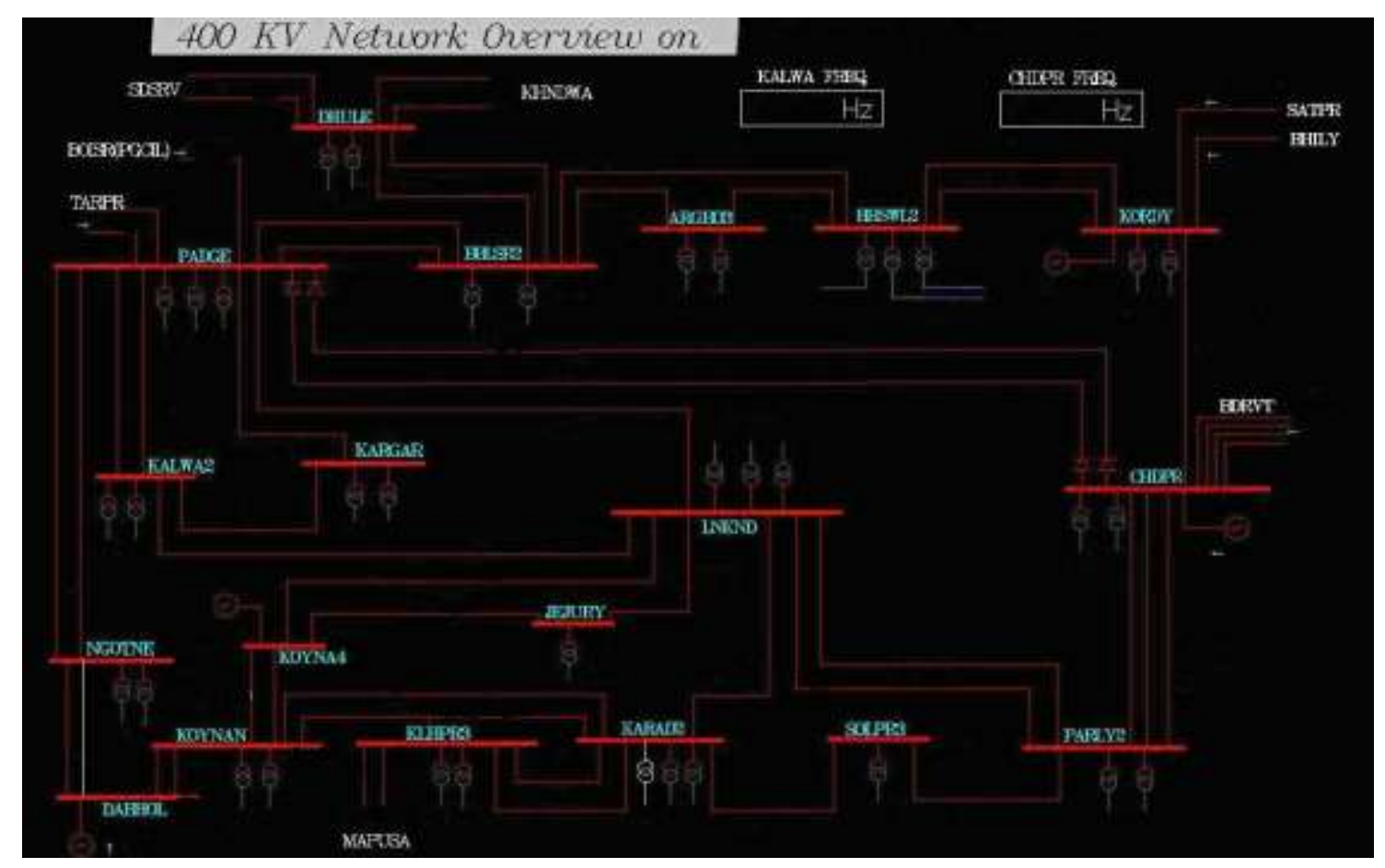

Figure A1: A Real 400 kV MSETCL, India

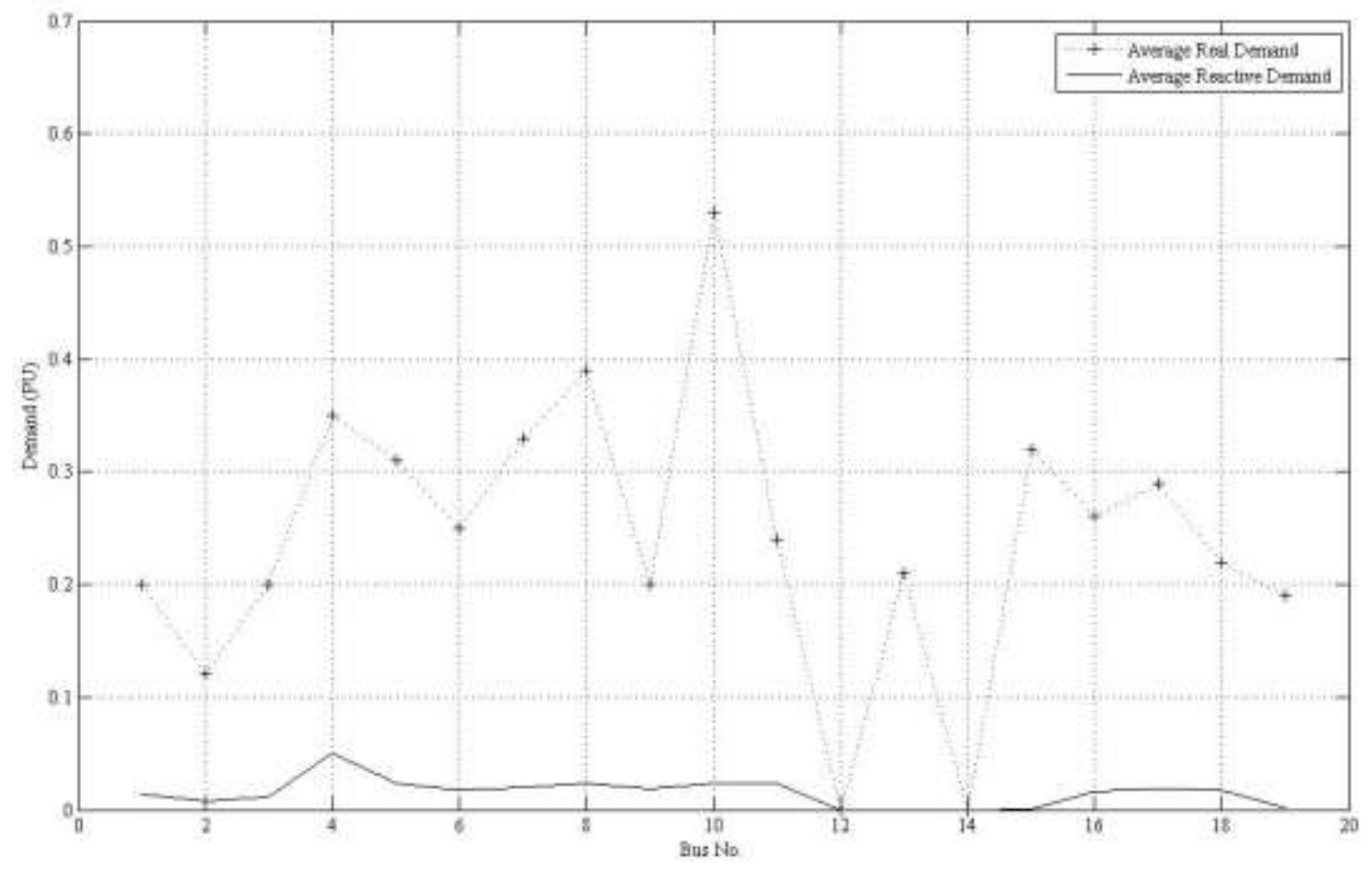

Figure A2: 400 kV MSETCL System: Electricity Demand Variation 